\title{
Use of the Herbal OTC Products and Dietary Supplements by Patients Receiving Chemotherapy: Survey-Based Study
}

\author{
Kowalczyk Adam¹, Bodalska Agnieszka1, Boszkiewicz Kamila², Karlowicz Bodalska Katarzyna ${ }^{3}$ \\ 1'Department of Pharmacognosy, Wroclaw Medical University, Faculty of Pharmacy, Borowska, Wroclaw, POLAND. \\ ${ }^{2}$ Department of Industrial Pharmacy, Wroclaw Medical University, Faculty of Pharmacy, Borowska, Wroclaw, POLAND. \\ ${ }^{3} \mathrm{CF}$ Hasco-Lek, Żmigrodzka, Wroclaw, POLAND.
}

\begin{abstract}
Context: Among cancer patients receiving chemotherapy, there is a growing trend to use self-medication. Many of them take preparations sold over the counter (OTC) and dietary supplements containing plant raw materials. Aims: The aim of this study is to evaluate the herbal OTC drug and dietary supplement usage among patients treated on the chemotherapy ward. Settings and Design: An anonymous survey was conducted among 92 patients of the chemotherapy ward of the Lower Silesian Oncology Center in Wroclaw (Poland) with the approval of the Bioethical Commission of the Medical University in Wroclaw (no KB-562/2014) and The Declaration of Helsinki. Methods and Material: An anonymous survey was conducted among 92 patients of the chemotherapy ward of the Lower Silesian Oncology Center in Wroclaw (Poland) in 2015. The questions concerned the use of herbal preparations by patients during chemotherapy. Statistical analysis used: The statistical analysis was developed using programs: Microsoft Office Excel 2007 and STATISTICA 10 (StarSoft Inc.). Analysis was performed by $\chi 2$ test. Results: The study has confirmed that the use of herbal OTC products and dietary supplements among cancer patients is a common occurrence. The main source of information about herbal preparations is the Internet and the most common place of purchase is a pharmacy. Conclusions: It is necessary to educate cancer patients to increase their awareness of the importance of a doctor's knowledge about all preparations that they take. Pharmacists play a very important role in self-medication of the patients. Thus, pharmacy students' education is needed in this field as well.
\end{abstract}

Key words: Herbal OTC products, Dietary supplements, Chemotherapy; Self-medication.

Key Messages: Usage of herbal OTC products by chemotherapy patients based on survey study is a common occurrence. Pharmacy is the main place of their purchase, therefore pharmacist should be well-educated in their role in self-medication of patients.

\section{INTRODUCTION}

Cancer is the second leading cause of death after cardiovascular diseases. ${ }^{1}$ In 2012, cancer was responsible for $26 \%$ of all deaths in men and $23 \%$ of deaths in women. In both sexes the most common cause of death is lung cancer. The second position in women's deaths is breast cancer, while in men it is colorectal cancer. The percentage will increase due to the aging of the population, as advancing age is one of the risk factors for cancer overall. ${ }^{2}$

Chemotherapy is one of the treatments for cancer though its use is associated with numerous side effects. Therefore, among cancer patients treated with chemotherapy, there is a growing trend to use self-medication, complementary and alternative medicine (CAM). ${ }^{3,4}$ Many patients take preparations sold over the counter (OTC)
Submission Date: 22-06-2017; Revision Date: 25-09-2017; Accepted Date: 16-10-2017

DOI: 10.5530/ijper.51.4s.98 Correspondence:

Dr. Kowalczyk Adam, Department of Pharmacognosy, Wroclaw Medical University, Faculty of Pharmacy, Borowska 211, 50-556 Wroclaw, POLAND. Phone no: +48 717840222 E-mail: adam.kowalczyk@ umed.wroc.pl

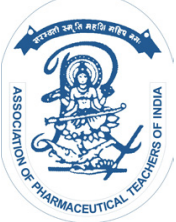

www.ijper.org 
and dietary supplements containing plant raw materials. Natural substances contained in plants have multidirectional pharmacological and chemopreventive action. Plant raw materials most commonly used by cancer patients are: garlic, nettle, thyme, ginger, milk thistle, echinacea, ginko, ginseng and valerian. ${ }^{5,6}$ Literature data indicates a potential antitumor activity of substances of vegetable origin, of which the most frequently cited are curcumin, resveratrol, artemisinin, berberine, piperine, mistletoe, green tea, broccoli. ${ }^{7}$ Conventional drug therapy combined with complementary medicine are increasingly used in cancer patients treatment. ${ }^{8,910}$

Universal access to information, (e.g. the Internet) results in patients willing to be actively involved in the healing process. ${ }^{11}$ Patients take natural preparations to strengthen the immune system, to slow the progression of cancer, and alleviate side effects associated with chemotherapy. ${ }^{6}$

The aim of this study is to evaluate the herbal OTC drug and dietary supplement usage among patients treated on the chemotherapy ward in the Lower Silesian Oncology Center in Wroclaw, Poland.

\section{SUBJECTS AND METHODS}

Ethical Consideration: An anonymous survey was conducted among 92 patients of the chemotherapy ward of the Lower Silesian Oncology Center in Wroclaw (Poland) with the approval of the Bioethical Commission of the Medical University in Wroclaw (no KB-562/2014) and The Declaration of Helsinki. All respondents gave informed consent.

Study Design: The study involved 57 women and 35 men in the period March- May 2015. The questions concerned, e.g. the use of herbal preparations during chemotherapy, where they purchase them and how often; if they inform physicians about their usage of these products or use them together with other medications; where they get knowledge about them; and whether or not the leaflet or information on the product package is sufficiently understandable. The patients rated, on a scale of 1 to 5 , their effectiveness and safety. Table 1 shows the sociodemographic data subjects.

Statistical Analysis: The statistical analysis was developed using programs: Microsoft Office Excel 2007 and STATISTICA 10 (StarSoft Inc.). Analysis was performed by $\chi^{2}$ test.

\section{RESULTS}

Half of the surveyed patients were positively disposed to herbal OTC drugs and dietary supplements, 30\%
Table 1: Title Sociodemographic data of patients

\begin{tabular}{|c|c|c|}
\hline Number of patients & $\mathbf{n = 9 2}$ & $\%$ \\
\hline \multirow{2}{*}{ Gender } & Women & $62 \%$ \\
\cline { 2 - 3 } & Men & $38 \%$ \\
\hline \multirow{3}{*}{ Education } & Primary & $7.6 \%$ \\
\cline { 2 - 3 } & Vocational & $21.7 \%$ \\
\cline { 2 - 3 } & High school & $41.3 \%$ \\
\hline \multirow{3}{*}{ Place of residence } & University & $29.4 \%$ \\
\cline { 2 - 3 } & Town below 20 000 & $33.7 \%$ \\
\cline { 2 - 3 } & $20000-100000$ & $38.0 \%$ \\
\hline
\end{tabular}

were rather positively disposed, and only $7.7 \%$ assessed these preparations negatively or rather negatively.

Among the surveyed patients $33.7 \%$ were unable to assess the effectiveness of herbal drugs, while $32.6 \%$ believed them to be rather effective, $6.5 \%$ believed them ineffective, and $4.3 \%$ rather ineffective. More than half of the patients $(62 \%)$ assessed the preparations taken as safe or rather safe compared to synthetic drugs. Only $5.4 \%$ of respondents did not rate the safety of herbal drugs positively. The correlation between the safety and efficacy of herbal preparations made by the $\chi 2$ test showed that $81 \%$ of patients evaluated herbal prepara tions as effective and rated their safety highly $\left(\chi^{2}=102.96\right.$; $\mathrm{df}=16 ; p<0.00001)$.

The most common sources of knowledge about herbal preparations among the responders was the Internet $(19.6 \%)$, the recommendation of a physician and/or pharmacist (14.1\%), recommendation of friends (13\%), and, most rarely, lectures $(1.1 \%)$. Based on the Levene's variance $(\chi 2=12.56 ; \mathrm{df}=4 ; \mathrm{p}=0.01)$ a correlation between the age of patients and usage of information sources about these preparations was demonstrated. It was found that the average age of people using the internet is lower than the average age of patients using other sources of information.

The vast majority of patients $(95.7 \%)$ declared that they read the leaflet attached to the product. The majority of respondents believed that the safety information contained in leaflets or on the package were sufficient $(32.6 \%)$ or rather sufficient $(31.5 \%)$. However one fifth of patients $(19.5 \%)$ considered them insufficient.

$81.5 \%$ of respondents made standalone purchases of herbal preparations. The most popular place to make purchases were a pharmacy $(64.1 \%)$ and medical shop $(27.2 \%)$, while the least popular was the internet $(2.2 \%)$. $23.9 \%$ of patients were buying herbal OTC drugs and dietary supplements once a month or more often, $21.7 \%$ once in two months, and $18.5 \%$ once in three months. There was a correlation between the opinion of patients 
about the effectiveness of herbal preparations and the frequency of their purchase. $\chi^{2}$ test showed that $45.5 \%$ of patients who bought herbal preparations once a month or more often, and $75 \%$ of them who made purchases once in two months considered them to be effective $\left(\chi^{2}=56,67 ; \mathrm{df}=24 ; \mathrm{p}=0,00019\right)$. Effectiveness influenced herbal product choice the most $(37.0 \%)$, followed by pharmacist $(14.1 \%)$ or doctor recommendation $(12.0 \%)$ and composition of preparation (13.0\%). The most commonly used herbal preparations were in the form of teas $(75 \%)$, while $25 \%$ of respondents used capsules, tablets, syrups and drops. Evaluation of the Levene's variance showed that $87 \%$ of patients with positive and $75 \%$ of patients with rather positive attitudes to herbal OTC drugs and dietary supplements used herbal teas $\left(\chi^{2}=12,56 ; \mathrm{df}=4 ; \mathrm{p}=0,01363\right)$. The most frequently used substances of plant origin are: cranberry fruit $(55.4 \%)$, garlic $(43.5 \%)$, St John's wort $(26.1 \%)$, aloe $(22.8 \%)$, apricot kernel $(22.8 \%)$ and milk thistle $(21.7 \%)$. Among other herbs, respondents most frequently indicated usage of chamomile $(2.2 \%)$ and mint $(2.2 \%)$. $78.3 \%$ of patients who had taken preparations say they fulfilled their expectations. Patients dissatisfied with the preparations were $10.9 \%$, while $10.8 \%$ were not able to answer this question. A statistically significant correlation between the opinion and attitude of the patient to the product, and satisfaction with the effects of its use was demonstrated. The preparations fully met the expectations of $80 \%$ of the respondents who defined their attitude to herbal medicines as rather positive and 95.5\% of patients who defined it as positive $\left(\chi^{2}=13,74 ; \mathrm{df}=4\right.$; $\mathrm{p}=0,00817)$.

$68.5 \%$ of respondents informed their doctors about taking herbal preparations, $28.3 \%$ did not inform and $3.2 \%$ did not answer this question.

\section{DISCUSSION}

A survey of patients undergoing chemotherapy in the Lower Silesian Oncology Center in Wroclaw confirmed that they used herbal OTC drugs and dietary supplements. The obtained data are consistent with studies conducted by Ebel et al. ${ }^{12}$

Other studies show that $52 \%$ of cancer patients use at least one form of complementary medicine, and $77 \%$ of them use herbal OTC medicines, dietary supplements and vitamins. ${ }^{13}$ Research by Alsanad et al., conducted in the UK, indicate that adult cancer patients use herbal preparations $(3.1 \%$ - 21.8\%) simultaneously with pharmacotherapy. ${ }^{7,14}$ In less developed countries a higher percentage of patients use herbal OTC drugs or dietary supplements, e.g. in Palestine 69.5\%, Malaysia $70.2 \%$, and Ethiopia $79 \% . .^{15,16}$

In this survey, women accounted for $62 \%$ of patients, similar to research by Ustundang. ${ }^{17}$

The internet was the main source of knowledge about herbal preparations for $19.6 \%$ of the respondents, while the recommendation of doctor and pharmacist accounted for $14.1 \%$. Similar results were obtained in studies conducted by the Turkish Oncology Group, which showed that for $16.7 \%$ of cancer patients, the internet is the main source of information, and, for $76 \%$, it was a credible source of information. ${ }^{18}$ These results are different from results obtained in American studies, in which the most common source of information about herbal preparations was a salesman in a health food store, and rarely was the recommendation of friends or the internet. ${ }^{12}$ The survey showed that the main place of purchase was a pharmacy $(64.1 \%)$, which is comparable to the results obtained by Bastani et al. in 2017. ${ }^{19}$ Pharmacists have a significant role in the patients' self-medication as health care providers and they have a key role in encouraging patients to cooperate with other health professionals like doctors or nurses. As the experts on drug therapy, pharmacists are obliged to take increased responsibility for the safe and effective use of medications, OTC products and food supplements also by patients during chemotherapy.

The most common substance of vegetable origin used by the respondents was cranberry $(55.4 \%)$. Less frequently mentioned were garlic, St John's wort, apricot kernel, aloe and milk thistle. The results obtained do not coincide with similar research conducted in the USA and Turkey, which is probably due to the different geographical location and regional traditions in the use of herbal preparations. ${ }^{5,6}$ Herbalism is perceived by patients as a natural and safe method of treatment, as shown in the research in which more than half of the respondents recognized that the herbal preparations are safer $(34.8 \%)$ or rather safer $(27.2 \%)$ compared to synthetic drugs. A study conducted among doctors from 16 countries of the Middle East, showed that herbal dietary supplements and herbal OTC medicines are the most commonly used addition to pharmacotherapy. Doctors, in contrast to the patients, are aware of the possibility of adverse effects with simultaneous use of synthetic drugs and herbal preparations. ${ }^{14,20}$

In the present study, it was shown that most of the respondents (68.5\%) informed the doctor about taking herbal preparations. This is a large percentage compared to the results of other surveys, in which only one fourth of patients informed the doctor about simultaneous use of synthetic drugs and herbal products. ${ }^{5}$ 


\section{CONCLUSION}

The study has confirmed that the use of herbal OTC drugs and dietary supplements among cancer patients is a common occurrence. The main source of information about herbal preparations is the Internet and the most common place of purchase is a pharmacy. It has been shown that among substances of plant origin, there are those which can cause interactions with co-administered synthetic drugs. It is therefore necessary to educate cancer patients to increase their awareness of the importance of a doctor's knowledge about all preparations that they take. Pharmacists play a very important role in self-medication of the patients by providing them the necessary information about the impact of dietary supplement and over the counter (OTC) products on the pharmacological treatment, about possible drug interactions and side effects. Thus, pharmacy students' education is needed in this field as well.

\section{CONFLICT OF INTEREST}

The authors declare no conflict of interest.

\section{ABBREVIATION USED}

OTC: Over the Counter; CAM: Complementary and Alternative Medicine.

\section{REFERENCES}

1. Siegel RL, Miller KD, Jemal A. Cancer statistics 2015.CA Cancer J Clin. 2015;65:5-29.

2. Pes GM, Cocco F, Bibbò S, Marras G, Dore MP. Cancer time trend in a population following a socio-economic transition: results of age-period-cohort analysis. Int J Public Health. 2017;62:407-14.

3. Engdal S, Steinsbekk A, Klepp O, Nilsen OG. Herbal use among cancer patients during palliative or curative chemotherapy treatment in Norway. Support Care Cancer. 2008;16: 763-9.

4. Robotin M, Holliday $C$, Bensoussan A. Defining research priorities in complementary medicine in oncology. Complement Ther Med. 2012;20:345-52.

5. Tuna S, Dizdar O, Calis M. The prevalence of usage of herbal medicines among cancer patients. JBUON. 2013;18:1048-51.

\section{PICTORIAL ABSTRACT}

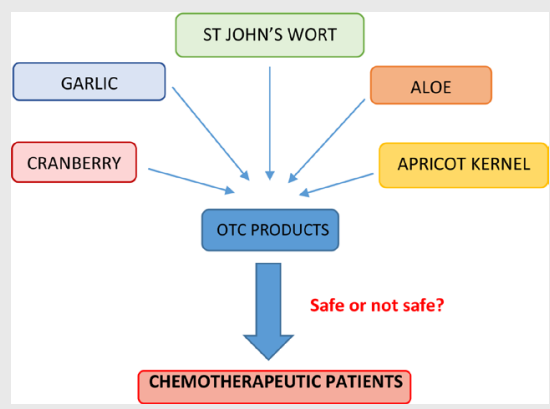

6. Gupta D, Lis CG, Birdsall TC, Grutsch JF. The use of dietary supplements in a community hospital comprehensive cancer center: implications for conventional care. Support Care Cancer. 2005;13:912-19.

7. Godsey J, Grundmann O. Review of various herbal supplements as complementary treatments for oral cancer. J Diet Suppl. 2016;13:538-50.

8. Yue Q, Gao G, Zou G, Yu H, Zheng X. Natural products as adjunctive treatment for pancreatic cancer: recent trends and advancements. Biomed Res Int. 2017, ID 8412508 https://www.hindawi.com/journals/bmri/2017/8412508/

9. Lim E, Vardy J, Oh B, Dhillon HM. Integration of complementary and alternative medicine into cancer-specific supportive care programs in Australia: A scoping study. Asia Pac J Clin Oncol. 2017;13:6-12.

10. Loquai C, Dechent D, Garzarolli M, Kaatz M, Kaehler KC, Kurschat $P$ et al. Use of complementary and alternative medicine: a multicenter crosssectional study in 1089 melanoma patients. Eur J Cancer. 2017;71:70-9.

11. Chang KH, Brodie R, Choong MA, Sweeney KJ, Kerin MJ. Complementary and alternative medicine use in oncology: a questionnaire survey of patients and health care proffesionals. BMC Cancer.20111;196: 1-9.

12. Ebel MD, Rudolph I, Keinki C, Hoppe A, Muecke R, Micke O et al. Perception of cancer patients of their disease, self-efficacy and locus of control and usage of complementary and alternative medicine. Cancer Res Clin Oncol. 2015;141:1449-55.

13. Zeller T, Muenstedt K, Stoll C, Schweder J, Senf B, Ruckhaeberle E et al. Potential interactions of complementary and alternative medicine with cancer therapy in outpatients with gynecological cancer in a comprehensive cancer center. J. Cancer Res Clin Oncol. 2013;139:357-65.

14. Alsanad SM, Howard RL, Williamson EM. An assessment of the impact of herb-drug combinations used by cancer patients. BMC. Complement Altern Med. 2016;16:393.

15. Ali-Shtayeh MS, Jamous RM, Salameh NM, Jamous RM, Hamadeh AM. Complementary and alternative medicine use among cancer patients in Palestine with special reference to safety-related concerns. J Ethnopharmacol. 2016;187:104-22.

16. Gan GG, Leong YC, Bee PC, Chin E, Teh AK. Complementary and alternative medicine use in patients with hematological cancers in Malaysia. Support Care Cancer. 2015;23: 2399-406.

17. Ustundag S, Demir Zencirci A. Complementary and alternative medicine use among cancer patients and determination of affecting factors: a questionnaire study. Holist Nurs Pract. 2015;29:357-69.

18. Nayir E, Tanriverdi O, Karakas Y, Kilickap S, Serdar Turhal N, Avci N et al. Tendency of cancer patients and their relatives to use internet for health-related searches: Turkish Oncology Group (TOG) Study. J BUON. 2016;21:714-19

19. Bastani P, Jooybar M, Zadeh MA, Samadbeik M. Community pharmacybased survey on pharmacists' knowledge, attitude, and performance regarding dietary supplements: evidence from south of Iran. J Physiol Pharm Pharmacol. 2017;7:396-402.

20. Ben-Arye E, Samuels N, Goldstein LH, Mutafoglu K, Omran S, Schiff E et al. Potential risk associated with traditional herbal medicine use in cancer care: a study of Middle Eastern oncology health care professionals. Cancer. 2016;122:598-610.

\section{SUMMARY}

- The use of herbal OTC drugs and dietary supplements among cancer patients is a common occurrence.

- Pharmacists play a very important role in selfmedication of the cancer patients.

Cite this article: Adam K, Agnieszka B, Kamila B, Katarzyna KB. Use of the Herbal OTC Products and Dietary Supplements by Patients Receiving Chemotherapy: Survey-Based Study. Indian J of Pharmaceutical Education and Research. 2017;51(4S):S675-S8. 